1 ANALYTICAL SCIENCE

7 \& TECHNOLOGY

Vol. 25, No. 6, 375-381, 2012

http://dx.doi.org/10.5806/AST.2012.25.6.375

\title{
NMHCs measurement using a cryogenic concentration system and application on gas samples
}

\author{
Su Ha Kim ${ }^{1,2}$, Dong Min Moon ${ }^{2}$ and Jin Seog Kim ${ }^{1,2, \star}$ \\ ${ }^{1}$ Science of Measurement, University of Science and Technology \\ 217 Gajung-ro Yuseong-gu, Daejeon, 305-350, Korea \\ ${ }^{2}$ Center for Gas Analysis, Korea Research Institute of Standards and Science \\ 267 Gajung-ro, Yuseong-gu, Daejeon, 305-340, Korea \\ (Received October 30, 2012; Revised November 21, 2012; Accepted November 21, 2012)
}

\section{저온농축장치를 이용한 $\mathrm{NMHCs}$ 의 측정법과 가스 시료에 적용 \\ 김수하 ${ }^{1,2} \cdot$ 문동민 $^{2} \cdot$ 김진석 ${ }^{12, \text { « }}$ \\ ${ }^{1}$ 과학기술연합대학원대학교 측정과학과, ${ }^{2}$ 한국표준과학연구원 대기환경표준센터 \\ (2012. 10. 30. 접수, 2012. 11. 21. 수정, 2012. 11. 21. 승인)}

\begin{abstract}
In this study, we have developed a cryogenic concentration system for the analysis of non-methane hydrocarbons (NMHCs) in air sample. NMHCs with $\mathrm{nmol} / \mathrm{mol}$ level of concentrations in the atmosphere were quantified by a comparative method with certified reference gas mixture. GC/FID with cryogenic concentration system operated in the range from $-67^{\circ} \mathrm{C}$ to $180^{\circ} \mathrm{C}$ was adopted. After cryogenic concentration, a fast desorption by heating could achieve a large amount of sample injection into the GC/FID. The linearity of the system was verified with the peak areas of NMHCs of the concentration amount of sample. The reproducibility is less than $10 \%$ and the limit of detection (LOD) is $0.1 \mathrm{nmol} / \mathrm{mol}$. For the application of this system, we analyzed NMHCs in gas samples taken from air and soil in Daejeon, Seosan and Goheung.

요 약: 본 연구에서는 테들러백에 포집한 가스 시료 중의 NMHCs 성분의 분석을 위한 저온농축장치 시 스템을 개발하였다. 개발한 저온농축장치는 냉동고를 이용하여 $-67{ }^{\circ} \mathrm{C}$ 에서 시료를 농축한 후 $180{ }^{\circ} \mathrm{C}$ 의 고온으로 탈착하는 시스템을 제작하였고, 많은 양의 시료가 GC/FID로 주입되게 함으로써 대기 중에 $\mathrm{nmol} /$ $\mathrm{mol}$ 농도 $(\mathrm{ppb})$ 의 미량으로 존재하는 가스의 정량을 가능하게 하였다. 저온농축장치의 신뢰성을 위해 수 행한 실험에서 농축시간과 피이크 면적이 비례함을 확인하였고, $10 \%$ 이내의 재현성과 $0.1 \mathrm{nmol} / \mathrm{mol}$ 의 검출한계를 확인하였다. 본 실험 방법을 실제 시료에 적용하기 위하여 대전, 서산, 고흥의 대기시료와 토 양시료에서 채취한 가스 중의 NMHCs를 분석하였다.
\end{abstract}

Key words: NMHCs, cryogenic pre-concentration, GC/FID

Corresponding author

Phone : +82-(0)42-868-5003 Fax : +82-(0)42-868-5042

E-mail : jkim@kriss.re.kr 


\section{1. 서 론}

인간의 산업활동이 급속히 발전함에 따라 발생하게 되는 NMHCs (non-methane hydrocarbons)는 $\mathrm{CH}_{4}$ 를 제 외한 $\mathrm{C}_{2}-\mathrm{C}_{12}$ 의 탄화수소로 구성되어 있다. ${ }^{1} \mathrm{NMHCs}$ 는 자동차, 연료가스 및 석유 정제시설, 주유소, 세탁소, 산업공정, biomass burning, oceanic source 등으로부터 발생하게 된다. ${ }^{2}$

$\mathrm{NMHCs}$ 는 대기 중에 $\mathrm{nmol} / \mathrm{mol}$ 농도(ppb)수준의 미 량으로 존재한다. 일반적으로 $\mathrm{C}_{3} \mathrm{H}_{8}$ 의 경우 아테네, 에 드몬튼 같은 도시는 $10 \mathrm{nmol} / \mathrm{mol}$ 이하의 농도수준을 보였으며, 차량과 생활환경이 많이 밀집되어 있을 것 이라 생각되는 멕시코 시티나 산티아고 같은 도시는 $100 \mathrm{nmol} / \mathrm{mol}$ 이상의 농도수준을 보인다. ${ }^{3}$

$\mathrm{NMHCs}$ 는 $\mathrm{NOx}$ 와 반응해 인간의 건강, 농업작물 그리고 숲에 부정적인 영향을 미치는 오존을 생성시 키기도 하고, ${ }^{1,4-6}$ 광화학 산화제 뿐 아니라 미세입자 생성에도 직접 또는 간접적으로 관여하여 광화학 스 모그를 유발시킬 수도 있다.,4,5 또한 NMHCs에 탄소 수가 증가하면 VOCs(Volatile Organic Compounds)가 된다. $2,5,6$ 위와 같은 여러 가지 문제를 야기하는 $\mathrm{NMHCs}$ 는 앞으로 우리나라에서도 정확한 측정이 요 구되며, 모니터링을 통해 경향성을 파악할 필요성이 있다.

$\mathrm{NMHCs}$ 와 같이 대기 중에 미량으로 존재하는 가스 는 가스 크로마토그래프/불꽃 이온화 검출기(Gas Chromatograph/Flame Ionization Detector, GC/FID)의 사 용만으로는 분석이 어렵다. 미량의 가스성분을 분석하 기 위해 농축, 흡착법을 사용하게 되는데 일반적으로 메두사(Medusa) (Scripps Institute of Oceanography, SIO, USA), TDS (Thermal Desorption System), CIS (Cryogenic Injection System)같은 시스템을 사용하고 있다. ${ }^{7,8}$ 이러 한 장치들의 농축과 흡착방법 원리를 이용하여 $\mathrm{NMHCs}$ 를 쉽고 빠르게 분석하는 최적의 조건을 만들 기 위한 저온농축장치(Cryogenic Concentration System) 를 개발하였다. 일반적으로 쓰이고 있는 농축장치는 자동화는 되어 있으나 halocarbons 분석에 맞추어져 있고, 분석시간의 효율성을 고려해 적합한 농축장치를 개발하였다.

본 실험은 개발한 농축장치와 연결된 $\mathrm{GC} / \mathrm{FID}$ 를 사 용하여 NMHCs 분석방법을 개발하였고, 유효성 파악 을 위해서 가스포집 방법 중 테들러백을 이용한 포집 법을 선택하여, ${ }^{9}$ 대기 시료와 해안습지 시료에 적용하 였다. 해안습지 시료는 직접적인 포집이 어려워 챔버
를 제작하여 테들러백에 포집하는 방법을 채택하여 수행하였다. ${ }^{10}$

\section{2. 실 험}

\section{1. $\mathrm{GC} / \mathrm{FID}$ 와 저온농축장치}

탄화수소류(hydrocarbons)는 일반적으로 GC/FID를 사용하여 분석한다. GC/FID (Agilent, HP6890, USA) 는 가스크로마토그래프에서 가장 널리 사용되고 있으 며, FID 검출기로 들어가는 탄소수에 따라 질량-감응 성(mass-sensitive)을 보인다.

대기 중의 NMHCs는 미량으로 존재하기 때문에 이 검출기의 사용만으로는 높은 감도 및 재현성을 기대 하기 어려워 농축장치를 사용하여 이들을 분석할 수 있는 시스템을 개발하였다. 개발된 농축장치는 냉동고 를 사용해 저온상태를 유지하게 하고, 온도조절 시스 템으로 연속적인 자동온도조절이 가능하며, 농축트랩 의 흡착제로서 $1 / 4$ inch 스테인리스 스틸(stainless steel) 관에 미국 SUPELCO사의 40-60 mesh size Carboxen ${ }^{\mathrm{TM}}$ 1000 을 사용하였다. ${ }^{11}$

초기 준비상태에서 $99.9999 \%$ 의 순수 헬륨가스(pure $\mathrm{He}$ )로 시료라인의 purging이 이루어지고, 저온상태의 냉동고가 연결된 온도조절 시스템의 온도가 $-67{ }^{\circ} \mathrm{C}$ 가 되면 시료를 일정 유량 $100 \mathrm{~mL} / \mathrm{min}$ 으로 5 분 동 안 흡착시켜 시료부피의 $0.5 \mathrm{~L}$ 를 농축하게 한다. 농축 과정 다음 10 초에 걸쳐 순수 헬륨가스를 농축 트랩 으로 주입하여 트랩에 가스 상태로 있는 질소 $\left(\mathrm{N}_{2}\right)$ 및 산소 $\left(\mathrm{O}_{2}\right)$ 바탕가스를 제거하는 과정을 거친 후 밸브를 작동하여 트랩을 밀폐시킨다. 밀폐된 저장장치에 농축 된 $\mathrm{NMHCs}$ 를 $180{ }^{\circ} \mathrm{C}$ 의 고온으로 빠르게 올려주어 5 분 동안 기화시킨 후, ${ }^{8}$ 많은 양의 시료를 GC/FID에 주입함으로써 각 성분에 대한 감도를 높일 수 있게 한다. 제작한 농축장치는 시료가 들어가 농축하는 과 정을 제외한 나머지 과정에서 순수 헬륨가스를 계속 흘려줌으로써 시료간의 오염을 방지하고, dead volume 을 줄여준다. 농축장치에서 $\mathrm{GC} / \mathrm{FID}$ 로 자동 주입되는 과정과 시료를 분석하기 위한 $\mathrm{GC} / \mathrm{FID}$ 의 분석조건은 각각 Fig. 1과 Table 1에 나타내었다.

\section{2. 표준물질}

$\mathrm{NMHCs}$ 의 정량은 KRISS의 일차표준물질(Primary Reference Material, PRM)로 비교 분석하였다. 이 분석에 사용된 표준물질은 $\mathrm{N}_{2}$ 바탕가스에 $\mathrm{CH}_{4}(50.37 \pm 0.15)$ $\mathrm{nmol} / \mathrm{mol}, \quad \mathrm{C}_{2} \mathrm{H}_{6}(49.87 \pm 0.15) \mathrm{nmol} / \mathrm{mol}, \quad \mathrm{C}_{2} \mathrm{H}_{4}(49.87 \pm$ 


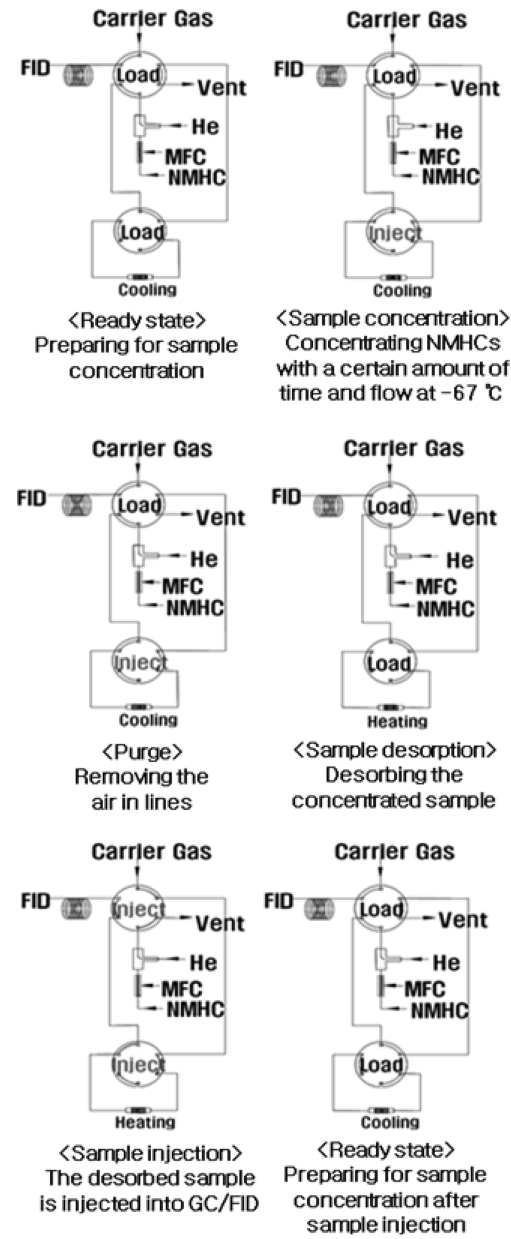

Fig. 1. Procedure of pre-concentration system.

Table 1. Analytical condition of GC/FID

\begin{tabular}{ll}
\hline \hline & Analytical Condition \\
\hline Column & Activated Alumina, $12 \mathrm{ft}$ \\
Oven temperature & $85^{\circ} \mathrm{C}, 21 \mathrm{~min}, 5^{\circ} \mathrm{C} / \mathrm{min}, 175{ }^{\circ} \mathrm{C}, 7 \mathrm{~min}$ \\
Carrier gas, flow & $\mathrm{N}_{2}, 28 \mathrm{~mL} / \mathrm{min}$ \\
Detector temperature & $250{ }^{\circ} \mathrm{C}$ \\
$\mathrm{H}_{2}$ flow & $45 \mathrm{~mL} / \mathrm{min}$ \\
Air flow & $450 \mathrm{~mL} / \mathrm{min}$ \\
Make up flow & $25 \mathrm{~mL} / \mathrm{min}$ \\
\hline
\end{tabular}

0.15) nmol $/ \mathrm{mol}, \quad \mathrm{C}_{3} \mathrm{H}_{8}(49.37 \pm 0.15) \mathrm{nmol} / \mathrm{mol}, \mathrm{C}_{3} \mathrm{H}_{6}$ (49.87 \pm 0.15$) \mathrm{nmol} / \mathrm{mol}, \mathrm{i}-\mathrm{C}_{4} \mathrm{H}_{10}(50.37 \pm 0.15) \mathrm{nmol} / \mathrm{mol}$, $\mathrm{n}-\mathrm{C}_{4} \mathrm{H}_{10}(50.37 \pm 0.15) \quad \mathrm{nmol} / \mathrm{mol}, \quad \mathrm{i}-\mathrm{C}_{5} \mathrm{H}_{12}(49.37 \pm 0.15)$ $\mathrm{nmol} / \mathrm{mol}, \quad 1-\mathrm{C}_{4} \mathrm{H}_{8}(49.87 \pm 0.15) \mathrm{nmol} / \mathrm{mol}, \mathrm{CO}_{2}(49.87 \pm$ $0.15) \mathrm{nmol} / \mathrm{mol}$ 가 혼합되어있다(불확도는 확장불확도 로서 신뢰범위는 $k=2$ ). PRM을 제조할 때, $\mathrm{N}_{2}$ 원료가
스에 NMHCs가 들어있지 않음을 확인하기 위해 $\mathrm{N}_{2}$ 원료가스의 순도 분석을 하였고, 분석하고자 하는 성 분의 NMHCs가 없다는 것을 확인하였다.

분석 장치의 드리프트(drift)를 보정하고, 분석 값의 신뢰성을 높이기 위하여 실린더에 압축한 건조 공기 를 작업용 표준물질(Working Standard)로 사용하였다. 작업용 표준물질은 대기성분 바탕가스에 $\mathrm{C}_{2} \mathrm{H}_{6}$ $(1.79 \pm 0.09) \mathrm{nmol} / \mathrm{mol}, \mathrm{C}_{2} \mathrm{H}_{4}(3.29 \pm 0.22) \mathrm{nmol} / \mathrm{mol}$, $\mathrm{C}_{3} \mathrm{H}_{8}(1.29 \pm 0.04) \mathrm{nmol} / \mathrm{mol}, \mathrm{C}_{3} \mathrm{H}_{6}(0.47 \pm 0.05) \mathrm{nmol} /$ $\mathrm{mol}, \mathrm{C}_{4} \mathrm{H}_{10}$ (3.20 \pm 0.10$) \mathrm{nmol} / \mathrm{mol}(k=1)$ 임을 $\mathrm{PRM}$ 과 비 교 분석하여 확인하였다.

\section{3. 가스 시료의 포집}

시료포집을 위한 장소는 우리나라 서해안과 남해안, 대전의 대기와 해안습지를 비교할 수 있는 곳으로 선 정하였다. 그 위치는 대전 한국표준과학연구원의 뒷산 과 서해안에 위치한 충남 서산시 고북면 부근 습지지 역, 남해안에 위치한 전남 고흥군 동일면 부근 습지지 역이다(Fig. 2).

시료 포집을 위해 사용한 테들러백(tedlar bag) (Sekikesukou, Japan)은 두께 $38 \mu \mathrm{m}$, 용량 $10 \mathrm{~L}$, 주입 구는 테프론(teflon) 재질의 외경 $6 \mathrm{~mm}$ 의 콕(cock) 타 입이다. 테들러백은 시료 포집에 앞서 안에 남아 있을 지도 모르는 불순물들을 제거하기 위하여 $99.9999 \%$ 의 순수 질소가스(pure $\mathrm{N}_{2}$ )로 두 차례 클리닝(cleaning) 한 것을 사용하였다. 테들러백의 안정성에 대해 포집 한 가스시료가 하루동안 변하지 않는다는 것을 확인 하였다. 각 지점의 대기 시료는 바람이 불어오는 방향 으로 바늘을 놓고 테들러백 안에 $6 \mathrm{~L}$ 정도 포집하였다. 해안습지 시료를 채취하기 위하여 챔버(chamber)를

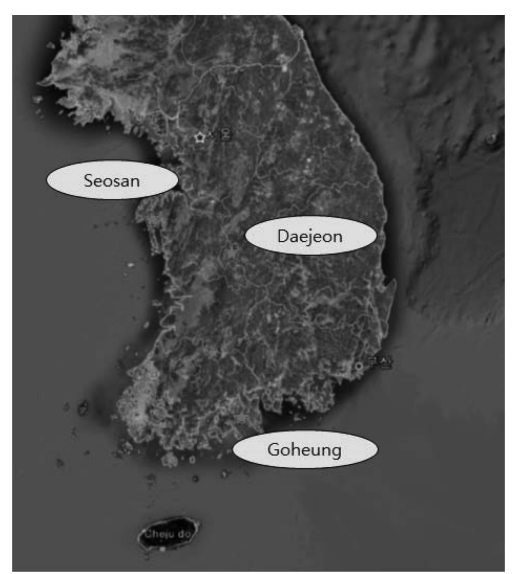

Fig. 2. Sampling sites. 


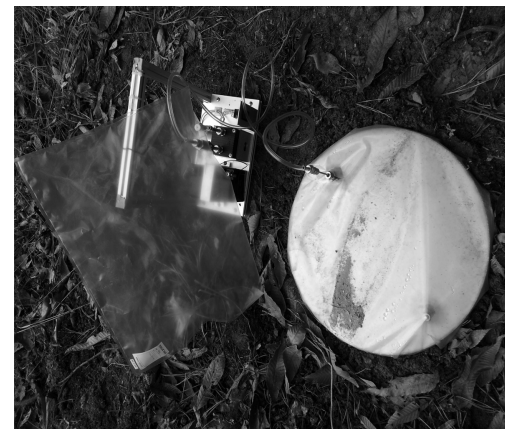

Fig. 3. Sampling system for chamber method: tedlar bag, air pump and chamber.

제작하였다. 챔버법은 토양이나 수표면으로부터 발산 되는 가스의 배출량을 직접적으로 측정할 수 있는 기 법이며, 국내외 온실가스 배출량 측정분석 연구에 많 이 사용되고 있다. ${ }^{10}$ 챔버는 지름이 $40 \mathrm{~cm}$, 높이가 20 $\mathrm{cm}$ 인 한 쪽이 막힌 원통모양의 스테인리스 스틸 재질 이며, 윗면에 두 개의 $1 / 4$ inch 포트를 부착하고 고무 막(septum)을 끼웠다. 시료포집 챔버를 땅 속에 묻고, 물이 스며드는 것을 방지하기 위해 겉을 비닐로 덮어 주었다. 한국표준과학연구원의 뒷산은 습지와 일반 토 양을 비교하기 위해 선택하였고, 서산시 습지지역에 민가 근처, 하천 근처, 길가에 각각 2 개의 챔버를, 고 흥군 습지지역에 2 개의 챔버를 묻었다. 땅 속에서 발 생하는 가스를 모으기 위해서 챔버를 시료 포집할 장 소에 묻고 한 달과 석 달이 지난 후에 시료포집을 수 행하였다.

땅 속에 묻은 시료의 포집은 $10 \mathrm{~L}$ 테들러백에 자체 제작한 $1 / 8 \mathrm{inch}$ 바늘이 연결된 다이어프램 펌프 (diaphragm pump)(GNL, Korea)를 이용하였고, $6 \mathrm{~L}$ 정 도 포집한 모습을 Fig. 3에 나타내었다. 대기 시료와 땅 속 시료는 실험실로 이동하여 포집 후 15 시간 내 에 분석을 하였다.

\section{3. 결과 및 고찰}

\section{1. 농축장치의 신뢰성}

분석시간의 효율성을 위해 실험한 농축시간에 따 른 감도 변화를 살펴보기 위해 작업용 표준물질을 사용하여 다른 조건은 동일하게 하고 농축시간만 5 분, 10 분, 15 분, 20 분, 25 분으로 달리하여 측정한 결과를 Fig. 4에 나타내었다. 측정 결과, 작업용 표준 물질의 성분들 중에서 $\mathrm{C}_{2} \mathrm{H}_{6}, \mathrm{C}_{3} \mathrm{H}_{8}, \mathrm{C}_{3} \mathrm{H}_{6}, \mathrm{i}-\mathrm{C}_{4} \mathrm{H}_{10}$,
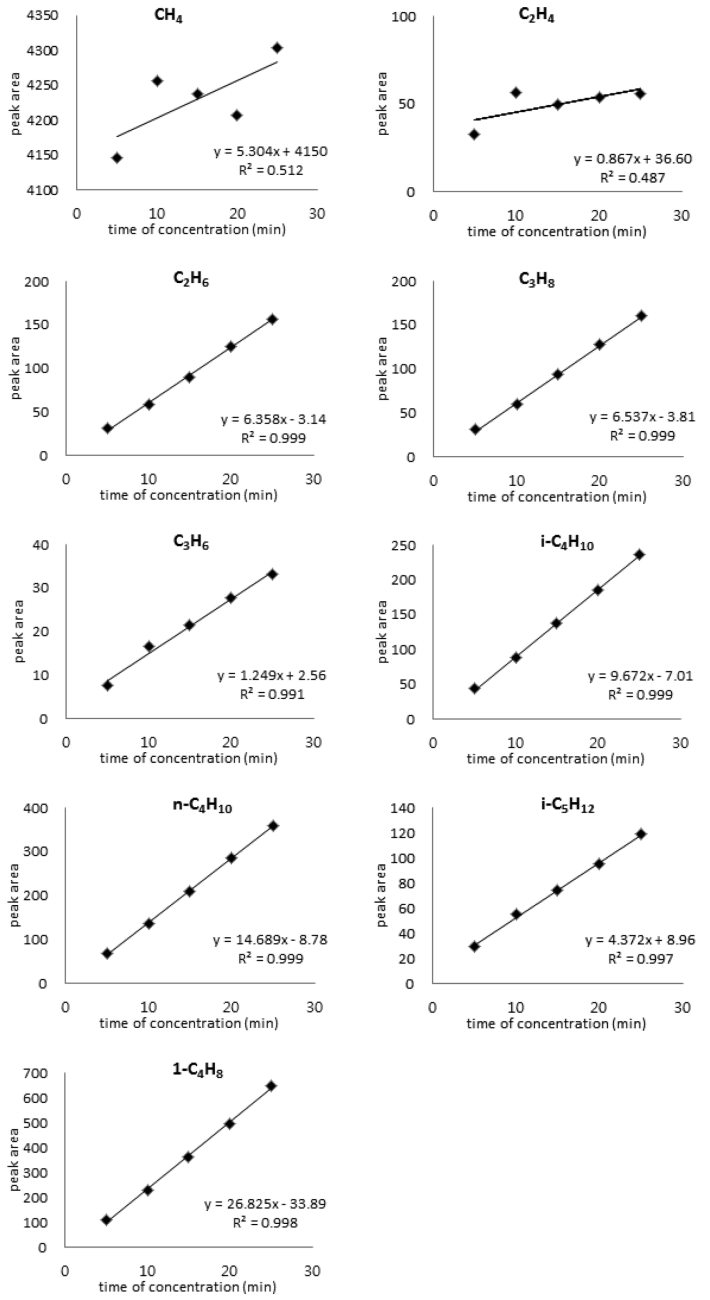

Fig. 4. Peak areas over concentration time on working standard.

$\mathrm{n}-\mathrm{C}_{4} \mathrm{H}_{10}, \mathrm{i}-\mathrm{C}_{5} \mathrm{H}_{12}, 1-\mathrm{C}_{4} \mathrm{H}_{8}$ 의 $\mathrm{R}^{2}=0.99$ 이상의 상관관 계를 보여 주었다. 하지만 상대적으로 분자량이 작 은 $\mathrm{CH}_{4}$ 와 $\mathrm{C}_{2} \mathrm{H}_{4}$ 는 농축이 잘 되지 않았다. 농축시간 이 길어질수록 더 높은 감도의 피이크를 얻을 수는 있으나 긴 시간에 따른 기기의 drift가 발생할 수 있 으므로, 각 시간대의 감도와 그 때의 검출한계를 비 교해 봤을 때, 5 분정도 농축하여 분석하는 방법을 선택하였다.

5 분 동안의 농축조건으로 작업용 표준물질을 사용 하여 각 성분에 대한 재현성(reproducibility)을 Table 2 에 나타내었다. 재현성은 다른 날 같은 작업용 표준물 질을 분석한 농도의 상대표준편차 $(\% \mathrm{RSD}$, Relative Standard Deviation)이다. 분석하고자 하는 $\mathrm{C}_{2}-\mathrm{C}_{4}$ 의 
Table 2. Reproducibility test of cryogenic concentration system

\begin{tabular}{ccccc}
\hline \hline Test Number & $\begin{array}{c}\mathrm{C}_{2} \mathrm{H}_{6} \\
(\mathrm{nmol} / \mathrm{mol})(\mathrm{nmol} / \mathrm{mol})(\mathrm{nmol} / \mathrm{mol})\end{array}$ & $\begin{array}{c}\mathrm{C}_{3} \mathrm{H}_{8} \\
\left.\mathrm{C}_{4} \mathrm{H}_{10} / \mathrm{mol}\right)\end{array}$ \\
\hline 1 & 1.82 & 1.32 & 0.44 & 3.29 \\
2 & 1.81 & 1.33 & 0.51 & 3.33 \\
3 & 1.70 & 1.35 & 0.50 & 3.25 \\
4 & 1.76 & 1.32 & 0.49 & 3.26 \\
5 & 1.72 & 1.36 & 0.50 & 3.27 \\
6 & 1.87 & 1.25 & 0.43 & 3.14 \\
7 & 1.91 & 1.27 & 0.45 & 3.08 \\
8 & 1.96 & 1.28 & 0.47 & 3.13 \\
9 & 1.89 & 1.27 & 0.40 & 3.09 \\
10 & 1.71 & 1.28 & 0.40 & 3.15 \\
11 & 1.77 & 1.29 & 0.46 & 3.27 \\
12 & 1.69 & 1.22 & 0.54 & 3.29 \\
13 & 1.70 & 1.24 & 0.55 & 3.23 \\
14 & 1.78 & 1.28 & 0.48 & 2.99 \\
\hline Average & 1.79 & 1.29 & 0.47 & 3.20 \\
Standard Deviation & 0.09 & 0.04 & 0.05 & 0.10 \\
\%, RSD & 4.87 & 3.20 & 9.71 & 3.17 \\
\hline
\end{tabular}

$\mathrm{NMHCs}$ 의 정량 결과는 재현성이 $\pm 10 \%$ 이내로 확인되 었다.

각 성분에 대한 검출한계(Limit Of Detection, LOD) 는 PRM을 사용하여 식 (1)에 의해 계산되었다. 가장
큰 값을 보인 $\mathrm{C}_{3} \mathrm{H}_{6}$ 에 대해서 $0.1 \mathrm{nmol} / \mathrm{mol}$ 로 계산되 었고, 다른 성분도 $0.1 \mathrm{nmol} / \mathrm{mol}$ 이내로 측정되었다.

$$
\operatorname{LOD}(\mathrm{PRM})=\frac{3 \times \text { noise } \times \text { concentration }}{\text { peak height }}
$$

\section{2. 가스 시료의 적용}

$\mathrm{PRM}$ 을 사용하여 실제 시료에 대하여 비교분석한 결과, 대상 성분이 $0.4 ~ 20 \mathrm{nmol} / \mathrm{mol}$ 농도수준을 보였 고, 대기시료에서는 지역, 계절에 따른 큰 차이를 찾 아볼 수는 없었다. 그러나 챔버에서 포집한 시료에서 는 여름에 이중 결합을 갖는 $\mathrm{C}_{3} \mathrm{H}_{6}$ 의 농도가 겨울보다 높은 농도로 측정되었다. 각 지점별로 분석한 시료의 농도는 Table 3에 나타내었다.

본 실험에서는 테들러백에 포집한 시료를 한 번만 분석을 했기 때문에 개수가 많을수록 편차가 적어진 다는 이론인 Poison theory를 적용해 각 시료농도의 불확도를 구하였다. ${ }^{12}$ 이때의 불확도는 작업용 표준물 질의 재현성을 활용하여 농도에 따른 불확도를 적용 하였다.

또한 분석한 각 지점의 농도에 기여하는 원인들을 알아보기 위해서 일반적으로 알려진 $\mathrm{LNG}, \mathrm{LPG}$ 의 성 분별 조성을 조사하여 Table 4에 나타내었다. ${ }^{13}$

Table 3와 Table 4를 바탕으로 각 지점에 대한 기여

Table 3. Data of sampling sites (in Daejeon, Seosan, Goheung)

\begin{tabular}{lcccc}
\hline \hline \multicolumn{1}{c}{ Sampling Sites } & $\begin{array}{c}\mathrm{C}_{2} \mathrm{H}_{6} \\
(\mathrm{nmol} / \mathrm{mol})\end{array}$ & $\begin{array}{c}\mathrm{C}_{3} \mathrm{H}_{8} \\
(\mathrm{nmol} / \mathrm{mol})\end{array}$ & $\begin{array}{c}\mathrm{C}_{3} \mathrm{H}_{6} \\
(\mathrm{nmol} / \mathrm{mol})\end{array}$ & $\begin{array}{c}\mathrm{C}_{4} \mathrm{H}_{10} \\
(\mathrm{nmol} / \mathrm{mol})\end{array}$ \\
\hline $\mathrm{WS}^{\mathrm{a}}$ & $1.79 \pm 0.09^{*}$ & $1.29 \pm 0.04$ & $0.47 \pm 0.05$ & $3.20 \pm 0.10$ \\
Daejeon G $^{\mathrm{b}}$ (W', 1 month) & $0.71 \pm 0.05$ & $0.41 \pm 0.02$ & $0.45 \pm 0.04$ & $1.71 \pm 0.07$ \\
Daejeon Air (W, 1 month) & $3.00 \pm 0.11$ & $1.64 \pm 0.05$ & $0.43 \pm 0.04$ & $0.89 \pm 0.05$ \\
Seosan G (W, H', 1 month) & $5.04 \pm 0.15$ & $4.51 \pm 0.08$ & $0.65 \pm 0.05$ & $1.91 \pm 0.08$ \\
Seosan G (W, roadside, 1 month) & $3.21 \pm 0.12$ & $2.22 \pm 0.05$ & $0.34 \pm 0.04$ & $0.71 \pm 0.05$ \\
Seosan G (W, R , 1 month) & $3.51 \pm 0.12$ & $2.46 \pm 0.06$ & $0.71 \pm 0.06$ & $0.86 \pm 0.05$ \\
Seosan Air (W, 1 month) & $3.58 \pm 0.12$ & $2.97 \pm 0.06$ & $0.99 \pm 0.07$ & $2.16 \pm 0.08$ \\
Daejeon G (W, 3 months) & $1.06 \pm 0.07$ & $1.41 \pm 0.04$ & $0.71 \pm 0.06$ & $5.80 \pm 0.14$ \\
Daejeon Air (W, 3 months) & $3.67 \pm 0.12$ & $2.25 \pm 0.05$ & $1.22 \pm 0.07$ & $5.56 \pm 0.13$ \\
Seosan G (W, H, 3 months) & $3.73 \pm 0.13$ & $2.56 \pm 0.06$ & $0.81 \pm 0.06$ & $4.48 \pm 0.12$ \\
Seosan G (W, R, 3 months) & $5.78 \pm 0.16$ & $4.61 \pm 0.08$ & $1.63 \pm 0.09$ & $5.89 \pm 0.14$ \\
Seosan Air (W, 3 months) & $3.28 \pm 0.12$ & $1.73 \pm 0.05$ & $0.93 \pm 0.06$ & $7.09 \pm 0.15$ \\
Goheung G (S , WL , 1 month) & $6.50 \pm 0.17$ & $3.98 \pm 0.07$ & $7.51 \pm 0.18$ & $2.55 \pm 0.09$ \\
Goheung G (S, L , 1 month) & $18.88 \pm 0.28$ & $16.21 \pm 0.15$ & $6.90 \pm 0.18$ & $10.74 \pm 0.19$ \\
Goheung Air (S, 1 month) & $3.53 \pm 0.12$ & $1.85 \pm 0.05$ & $5.99 \pm 0.16$ & $1.49 \pm 0.07$ \\
Daejeon G (S, 1 month) & $2.95 \pm 0.11$ & $1.71 \pm 0.05$ & $3.21 \pm 0.12$ & $0.97 \pm 0.06$ \\
Daejeon Air (S, 1 month) & $3.64 \pm 0.12$ & $0.98 \pm 0.04$ & $2.85 \pm 0.11$ & $1.19 \pm 0.06$ \\
\hline
\end{tabular}

${ }^{\mathrm{a}} \mathrm{WS}=$ Working Standard, ${ }^{\mathrm{b}} \mathrm{G}=$ in the ground, ${ }^{\mathrm{c}} \mathrm{W}=$ winter, ${ }^{\mathrm{d}} \mathrm{S}=$ summer, ${ }^{\mathrm{e}} \mathrm{H}=$ near houses, ${ }^{\mathrm{f}} \mathrm{R}=$ near river, ${ }^{\mathrm{g}} \mathrm{WL}=$ wetland, ${ }^{\mathrm{h}} \mathrm{L}=$ lawn "Uncertatinties in concentration are $k=1$ 
Table 4. Component ratio of LNG and LPG (from household gas and motor vehicle gas)

\begin{tabular}{lrccrr}
\hline \hline Component & LNG & $\begin{array}{c}\text { LPG } \\
\left(\mathrm{H}^{\mathrm{a}} \text {, winter }\right)\end{array}$ & $\begin{array}{c}\text { LPG } \\
(\mathrm{H}, \text { summer })\end{array}$ & $\begin{array}{c}\text { LPG } \\
\left(\mathrm{M}^{\mathrm{b}} \text {, winter }\right)\end{array}$ & $\begin{array}{c}\text { LPG } \\
(\mathrm{M} \text {, summer })\end{array}$ \\
\hline $\mathrm{CH}_{4}$ & $90.68 \%$ & $<1 \mathrm{ppm}$ & $<1 \mathrm{ppm}$ & $0.02 \%$ & $0.01 \%$ \\
$\mathrm{C}_{2} \mathrm{H}_{6}$ & $6.00 \%$ & $0.90 \%$ & $0.42 \%$ & $0.64 \%$ & $0.22 \%$ \\
$\mathrm{C}_{2} \mathrm{H}_{4}$ & $<1 \mathrm{ppm}$ & $<1 \mathrm{ppm}$ & $<1 \mathrm{ppm}$ & $<1 \mathrm{ppm}$ & $<1 \mathrm{ppm}$ \\
$\mathrm{C}_{3} \mathrm{H}_{8}$ & $2.12 \%$ & $97.51 \%$ & $98.76 \%$ & $32.46 \%$ & $5.66 \%$ \\
$\mathrm{C}_{3} \mathrm{H}_{6}$ & $0.001 \%$ & $0.02 \%$ & $0.03 \%$ & $0.15 \%$ & $0.10 \%$ \\
$\mathrm{C}_{4} \mathrm{H}_{10}$ & $0.97 \%$ & $1.57 \%$ & $0.79 \%$ & $62.97 \%$ & $89.68 \%$ \\
Others & $0.21 \%$ & - & - & $3.75 \%$ & $4.32 \%$ \\
\hline
\end{tabular}

${ }^{\mathrm{a}} \mathrm{H}=$ for household gas, ${ }^{\mathrm{b}} \mathrm{M}=$ for motor vehicle gas

성분을 알아보기 위해 비율에 대한 그래프를 그렸다. Fig. 5에서는 $\mathrm{C}_{3} \mathrm{H}_{6} / \mathrm{C}_{3} \mathrm{H}_{8}$ 에서 Fig. 6에서는 $\mathrm{C}_{2} \mathrm{H}_{4} / \mathrm{C}_{3} \mathrm{H}_{8}$ 와 $\mathrm{C}_{3} \mathrm{H}_{6} / \mathrm{C}_{3} \mathrm{H}_{8}$ 에서 여름 데이터들에 대하여 특히 높은 비율의 특이성을 보였다. 그래프에서 $\mathrm{LPG}$ 와 $\mathrm{LNG}$ 의 위치는 아주 적은 비율의 $\mathrm{C}_{2} \mathrm{H}_{4}$ 와 $\mathrm{C}_{3} \mathrm{H}_{6}$ 를 포함하고 있 어 $\mathrm{LPG}$ 와 $\mathrm{LNG}$ 의 노출이 원인이 아닌 것으로 판단되 며, 그보다는 온도 상승으로 인해 bio-activity가 활발 해 짐에 따라 이들로부터 방출되었을 가능성이 높으 며, 이를 뒷받침하는 연구결과들도 발표된바 있다. ${ }^{14-17}$ $\mathrm{C}_{2} \mathrm{H}_{4}$ 은 농축시간에 따른 직선성은 좋지 않았지만, 이 중결합을 갖는 성분의 특이성의 비교를 위해 그래프

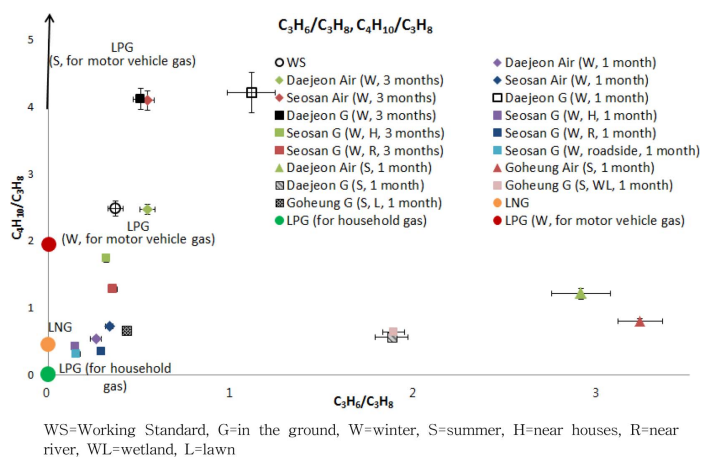

Fig. 5. Ratio graph of $\mathrm{C}_{3} \mathrm{H}_{6} / \mathrm{C}_{3} \mathrm{H}_{8}$ and $\mathrm{C}_{4} \mathrm{H}_{10} / \mathrm{C}_{3} \mathrm{H}_{8}$.

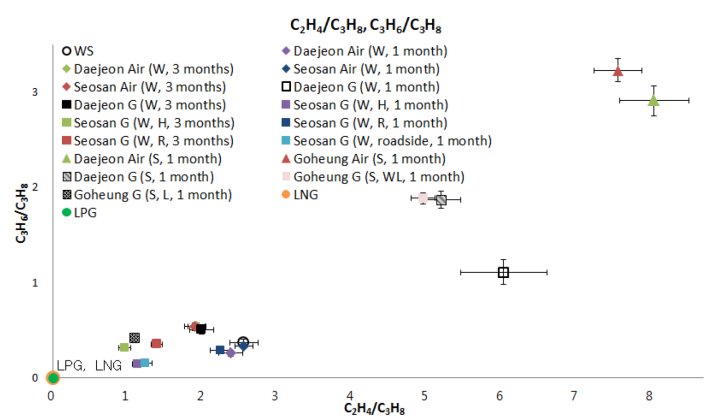

Fig. 6. Ratio graph of $\mathrm{C}_{2} \mathrm{H}_{4} / \mathrm{C}_{3} \mathrm{H}_{8}$ and $\mathrm{C}_{3} \mathrm{H}_{6} / \mathrm{C}_{3} \mathrm{H}_{8}$.
에 사용되었다. Fig. 5와 Fig. 6에서 보이는 것과 같이 한 달 동안 묻은 대전의 땅 속 시료는 낮은 농도의 $\mathrm{C}_{3} \mathrm{H}_{8}$ 의 영향으로 $\mathrm{C}_{2} \mathrm{H}_{4} / \mathrm{C}_{3} \mathrm{H}_{8}$ 와 $\mathrm{C}_{3} \mathrm{H}_{6} / \mathrm{C}_{3} \mathrm{H}_{8}, \mathrm{C}_{3} \mathrm{H}_{6} / \mathrm{C}_{3} \mathrm{H}_{8}$ 와 $\mathrm{C}_{4} \mathrm{H}_{10} / \mathrm{C}_{3} \mathrm{H}_{8}$ 의 비율 값이 커진 것이다.

또 다른 특이성으로 습지에 묻은 지 한 달이 지난 후에 분석했을 때, Fig. 7과 Fig. 8에서 보는 것과 같 이 $\mathrm{C}_{2} \mathrm{H}_{6}, \mathrm{C}_{3} \mathrm{H}_{8}$ 성분이 다른 성분들에 비해 높은 비율 을 보여 주었다. 이 비율은 다른 대기시료나 습지시료 보다도 높은 비율이었고, 분모를 다른 성분으로 놓아 도 비슷하게 나타났다. 각 성분의 비율로 그려진 그래 프를 바탕으로 추정해 볼 때, $\mathrm{LNG}$ 성분과 유사한 탄 화수소가 습지에서 발생하였음을 볼 수 있다.

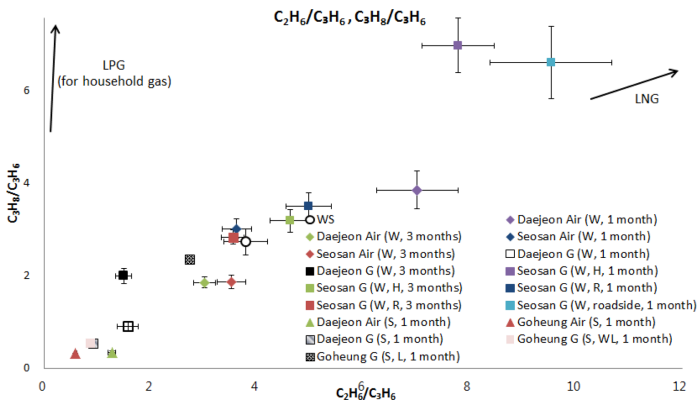

Fig. 7. Ratio graph of $\mathrm{C}_{2} \mathrm{H}_{6} / \mathrm{C}_{3} \mathrm{H}_{6}$ and $\mathrm{C}_{3} \mathrm{H}_{8} / \mathrm{C}_{3} \mathrm{H}_{6}$.

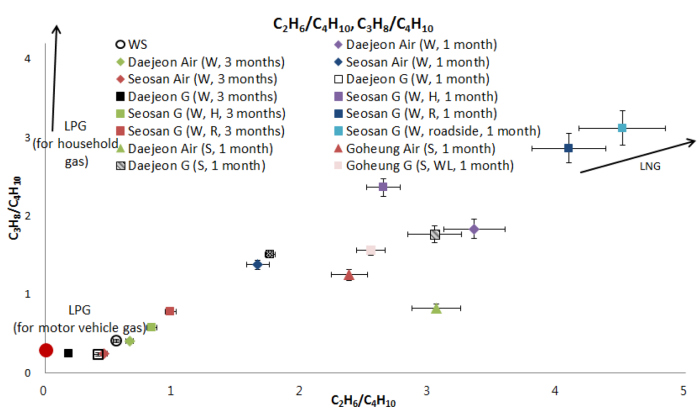

Fig. 8. Ratio graph of $\mathrm{C}_{2} \mathrm{H}_{6} / \mathrm{C}_{4} \mathrm{H}_{10}$ and $\mathrm{C}_{3} \mathrm{H}_{8} / \mathrm{C}_{4} \mathrm{H}_{10}$. 


\section{4. 결 론}

본 연구에서는 아직 확립되지 않은 저농도의 $\mathrm{NMHCs}$ 의 분석을 위해 저온농축장치를 개발하였다. 동일한 다른 조건에서 개발한 농축장치의 농축시간에 따른 감도변화를 알아보기 위해 수행한 실험에서 $\mathrm{C}_{2} \mathrm{H}_{6}, \mathrm{C}_{3} \mathrm{H}_{8}, \mathrm{C}_{3} \mathrm{H}_{6}, \mathrm{i}-\mathrm{C}_{4} \mathrm{H}_{10}, \mathrm{n}-\mathrm{C}_{4} \mathrm{H}_{10}, \mathrm{i}-\mathrm{C}_{5} \mathrm{H}_{12}, 1-\mathrm{C}_{4} \mathrm{H}_{8}$ 이 $\mathrm{R}^{2}=0.99$ 이상의 상관관계를 보여 농축시간이 증가함 에 따라 농축이 비례적으로 되었음을 확인하였다. 농 축장치를 사용하여 $\mathrm{GC} / \mathrm{FID}$ 로 대기 중 $\mathrm{NMHCs}$ 을 측 정할 때 $\pm 10 \%$ 이내의 측정불확도 $(k=1)$ 를 나타냈고 검 출한계는 $0.1 \mathrm{nmol} / \mathrm{mol}$ 이내로 분석할 수 있음을 알 수 있었다.

이 농축장치를 대기시료와 토양시료에서 발생하는 $\mathrm{NMHCs}$ 를 정량하는데 적용하였다. 적용 결과, 한 두 번의 시료채취만으로는 대기시료에서 뚜렷한 계절별, 지역별 특이성을 찾지 못하였다. 그러나 NMHCs는 건강과 환경에 좋지 않은 영향을 주는 오존생성, 광화 학 스모그유발, VOCs 생성 등에 관여하므로 꾸준한 모니터링을 통한 NMHCs의 경향성 파악이 필요할 것 으로 보인다.

개발한 농축장치를 챔버법을 사용하여 포집한 토양 에서 발생하는 가스 시료에 적용해 본 결과, 특이성으 로 여름 토양에서 이중 결합을 갖는 $\mathrm{NMHCs}$ 가 높은 비율을 보였다. 이는 온도 상승에 따른 bio-activity의 활동이 활발해짐에 따른 것으로 보이며 뒷받침하는 연구결과들도 발표된바 있다. 또한, 서산의 겨울 습지 에서는 상대적으로 높은 비율의 $\mathrm{C}_{2} \mathrm{H}_{6}, \mathrm{C}_{3} \mathrm{H}_{8}$ 를 볼 수 있는 특이성을 발견할 수 있었다.

\section{감사의 글}

본 연구는 기초기술연구회, 한국표준과학연구원의 국가 의제연구(National Agenda Project, 과제번호 NAP-08-2)의 지원을 받아 수행되었으며, 이에 감사드 립니다.

\section{참고문헌}

1. C. T. Vincent, BSc(Hons.), Measurement of atmospheric hydrocarbons and air quality in Hong kong, The Hong Kong Polytechnic university (1998).

2. E. J. Lim, Y. S. Kim and B. M. Kim, Korea Soc. Atmos. Envir, PA43, 289-290 (2003).

3. K. L. So and T. Wang, Sci. Total Envir, 328(1-3), 161174 (2004).

4. Erik Velasco, Atmos. Envir, 37(5), 625-637 (2003).

5. S. J. Liaw and T. L. Tso, Anal. Sci. Technol., 8(4), 807814 (1995).

6. S. J. Jeon, B. J. Kim, J. S. Kim and G. S. Heo, Anal. Sci. Technol., 12(4), 332-340 (1999).

7. KRISS, Development of measurement technology for solving climate change, KRISS/IR-2012-026, KRISS, 185-194 (2012).

8. KRISS, Development of national standard PFCs greenhouse gas and establishment of continuous on line measurement system, KRISS/IR-2006-078, KMA, 2241 (2006)

9. M. G. Kim, Y. L. Jung, Y. M. Seo, S. H. Nam and Y. J. Gwon, Anal. Sci. Technol., 14(3), 274-285 (2001).

10. KRISS, Development of measurement methods for solving climate change, KRISS/IR-2011-074, KRCF (2011).

11. M. K. Lee, Characteristic of a sorption trap preconcentrator for trace analysis of volatile organic compounds in air samples, Wonkwnag university (2009).

12. KRISS, Evaluation of measurement uncertainty of the foundation for beginners, 15-19 (2011).

13. J. Tan, S. Guo, Y. Ma, K. He, F. Yang, Y. Yu and J. Wang, Envir. Monitor. Assess., 183(1-4), 297-305 (2011).

14. I. Devai and R. D. Delaune, Water, Air and Soil Poll., 88(1-2), 39-46 (1996).

15. A. Guenther, C. Geron, T. Pierce, B. Lamb, P. Harley and R. Fall, Atmos. Envir, 34(12-14), 2205-2230 (2000).

16. H. Hellen, H. Hakola, K.-H. Pystynen, J. Rinne and S. Haapanala, Biogeosciences, 3, 167-174 (2006).

17. L. Donoso, R. Romero, A. Rondon, E. Fernandez, P. Oyola and E. Sanhueza, J. Atmos. Chem., 25, 201-214 (1996). 